\title{
Epigallocatechin-3-gallate cross-linked small intestinal submucosa for guided bone regeneration
}

Min Gou, ${ }^{a}$ Yi-Zhou Huang, ${ }^{b}$ Jun-Gen Hu, ${ }^{b}$ Yan-Lin Jiang, ${ }^{b}$ Xiu-Zhen Zhang, ${ }^{b}$ Nai-Chuan Su, ${ }^{a}$ Yi Lei, ${ }^{b}$ Hai Zhang, ${ }^{c}$ Hang Wang ${ }^{\star a}$ and Hui-Qi Xie ${ }^{\star b}$

Supporting Information

2 pages, 1 figure. 


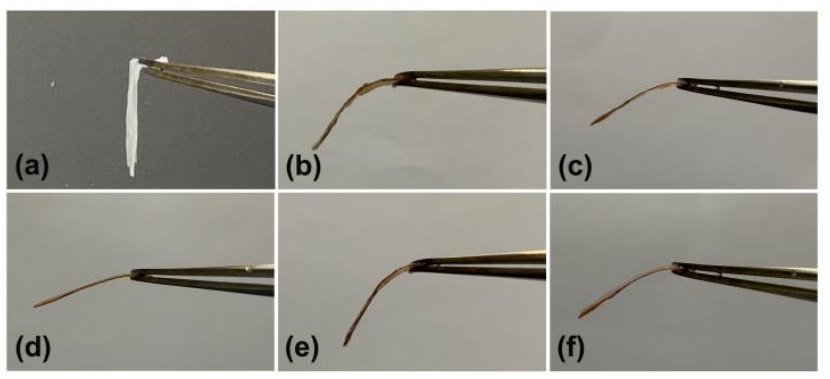

Fig. S1 Images showing the handling properties of wet SIS and E-SIS. (a) SIS, (b) $0.1 \%$ E-SIS, (c) $0.25 \%$ E-SIS, (d) $0.5 \%$ E-SIS, (e) $1 \%$ E-SIS, (f) $2 \%$ E-SIS. 